\title{
Molecular dynamics simulation of adsorption of an oil-water-surfactant mixture on calcite surface
}

\author{
Lu Guiwu ${ }^{1 *}$, Zhang Xuefen ${ }^{1}$, Shao Changjin ${ }^{1}$ and Yang Hong ${ }^{2}$ \\ ${ }^{1}$ Department of Mathematics and Physics, China University of Petroleum, Beijing 102249, China \\ ${ }^{2}$ Basic Department of Beijing Information Engineering College, Beijing 100081, China
}

\begin{abstract}
An interface super molecular structure model for oil-water-surfactant mixture and calcite was established. By using a molecular dynamics method, the effects of rhamnolipid, sodium dodecyl benzene sulfonate and sodium hexadecyl sulfonate on the interface adsorption behavior of oil molecules were investigated. It was found that these three surfactants could reduce oil-calcite interface binding energy, and play a role of oil-displacing agent.
\end{abstract}

Key words: Oil, calcite, adsorption, molecular dynamics

\section{Introduction}

Reservoir rock is a high-energy surface material with well-developed pores and large surface/volume ratio. It can strong adsorb polar molecules, such as surface active species and polymers in the reservoir bed. This adsorption might result in the change of reservoir bed wettability, plugging the pore throat, and in addition damaging the reservoir bed ( $\mathrm{He}$ and Hua, 1995). The adsorption of reservoir rock makes the residual oil (after water drive) cover the rock surface and form oil films. Sometimes the volume of oil film may account for up to $20 \%$ of the total pore volume, and become the main part of the residual oil (Bi et al, 1997). Therefore, investigation of rock surface adsorption behavior has attracted considerable interest.

Adsorption of oil on rock surfaces is a complicated physical and chemical process. The constitution and structure of rock, crude oil and surfactant (which is injected in the tertiary recovery process) could change the adsorption characteristics. Meanwhile, crude oil is a very complicated mixture. It is a heavy workload to select or synthesize a proper surfactant by using conventional laboratory methods and it is very costly and uncertain. In this work, molecular dynamics (MD) simulation is used to study the dynamics of oil and water adsorption on calcite, an abundant carbonate mineral. MD is a powerful method for investigating adsorption behavior at molecular level, and it can provide an insight into structural and dynamic information associated with the adsorption process. Previous MD research into adsorption behavior was aimed at mineral structure and chemical reaction activity. For example, ab initio molecular orbital studies of the effects of basis set size on the calculated structure and acidity of hydroxyl groups (Nicholas et al, 1992a; 1992b), the clay-water interface structure and the

*Corresponding author. email: lugw@cup.edu.cn Received September 8, 2008 hydration characteristics of clay (Delville, 1991; Boek et al, 1995), and the effect of ion on hydrating expansion (Boek et al, 1995). Recently, molecular dynamics research on adsorption enthalpy includes hydrocarbon compounds on the surface of montmorillonite, , trichloroethylene on kaolin and pyrophyllite surfaces, and humic material on an oxidized lignin surface (Teppen et al, 1997; Shevchenko et al, 1999; Cakova et al, 1999).

The (1) $\overline{10}$ plane of calcite has been subjected to many experimental and theoretical investigations, as it is the most stable crystal plane of calcite (Hädicke et al, 1999; Rieger et al, 1997). Many studies have been aimed at understanding crystal growth, dissolution, and structure of calcite and its polymorphs. To determine the surface structure of calcite, several studies have been carried out by using a variety of surface sensitive techniques (Liang et al, 1996). Using X-ray photoelectron spectroscopy and low-energy electron diffraction, Stipp and Hochella (1991) have showed the immediate formation of hydrate species on a calcite surface prepared under various atmospheres and in different aqueous solutions. Kendall and Martin (2007) have shown similar hydrate patches on a calcite surface with atomic force microscopy. Ab initio studies have predicted that if a hydroxyl group was placed just above each of the surface calcium ions and a hydrogen atom was added to each surface carbonate group (to the surface oxygen atom) (Kerisit et al, 2003), the added surface hydrogen atom would form a bond with the surface hydroxyl group, and in this way a water molecule is generated. This suggests that the associative adsorption of water on calcite surface is favorable. The energetics of adsorption of water on the calcite surface have previously been investigated by using MD simulations by de Leeuw and co-workers (de Leeuw and Parker, 1997). The free energy of the adsorption of water and metal ions (magnesium, calcium, and strontium) on the (104) calcite surface has also been previously determined by using MD simulations (Kerisist and Parker, 2004). Shi et al. (2006) have studied the interaction 
between carboxylate copolymer and calcite crystal. This study suggests that nonstoichiometric surfaces play an important role in the chemistry of calcite at high $\mathrm{pH}$. In our work, three kinds of surfactant (i.e. sodium dodecyl benzene sulfonate, sodium hexadecyl sulfonate and rhamnolipid biosurfactant) were used to investigate their effects on oil molecules adsorption behavior on calcite surface. It gives some physical insight into the micro adsorption characteristics on reservoir rock surfaces.

\section{Modeling and simulation}

\subsection{Simulation of force-field}

All the simulations were performed by using the Material Studio 4.0 from Accelrys, Inc. (formerly Molecular Simulation, Inc.). All the potential parameters were based on the Condensed-phase Optimized Molecular Potentials for Atomistic Simulation Studies (COMPASS). It is the first ab initio force field that has been parameterized and validated by using condensed-phase properties in addition to various $\mathrm{ab}$ initio and experimental data for molecules in isolation (Sun, 1998). Consequently, this force field enables accurate and simultaneous prediction of structural, conformational, vibrational, and thermophysical properties for a broad range of molecules in isolation and in condensed phases, and under a wide range of conditions of temperature and pressure.

\subsection{Modeling}

Calcite belongs to the $R \overline{3} c$ space group. The unit cell parameter is $a=b=0.4988 \mathrm{~nm}, c=1.7061 \mathrm{~nm}, \alpha=\beta=90^{\circ}, \gamma=120^{\circ}$ (Graf, 1961). The atomic structure model of calcite is shown in Fig. 1. The Crystal Builder is used to create a 27-unite cell slab of calcite and the Surface Builder module is used to create the $(1 \overline{10})$ surface. The system size of the simulated rock is $4.491 \times 5.1845 \times 1.375 \mathrm{~nm}^{3}$. It contains three layers of calcium and carbonate ions with a total of 2,430 atoms. In order to guarantee the size of this crystal being sufficient and that no distortion of the lattice would occur, we use the Discover Minimizer to minimize the energy of the crystal when applying the periodic condition. Octane was selected as an organic phase in these MD simulations. Sodium dodecyl benzene sulfonate $\left(\mathrm{CH}_{3}\left(\mathrm{CH}_{2}\right)_{10} \mathrm{CH}_{2} \mathrm{C}_{6} \mathrm{H}_{4} \mathrm{SO}_{3} \mathrm{Na}\right)$, sodium hexadecyl sulfonate $\left(\mathrm{CH}_{3}\left(\mathrm{CH}_{2}\right)_{14} \mathrm{CH}_{2} \mathrm{SO}_{3} \mathrm{Na}\right)$ and biosurfactant rhamnolipid were selected as the surface surfactants.

Since both octane and surface surfactant have a large alkyl chain, the first step is to optimize their energy. The optimized model is shown in Fig. 2. The model of oil, water and the mixed system with surfactant was set up by using the Amorphous Cell module. The number of oil molecules is 60, water molecules 1200 , and surfactant molecules 5 or 3 , and the density is $0.91 \mathrm{~g} / \mathrm{cm}^{3}$. The unit supercell parameters $\mathrm{a}, \mathrm{b}$ of the amorphous structure are the same as the parameters of calcite surface.

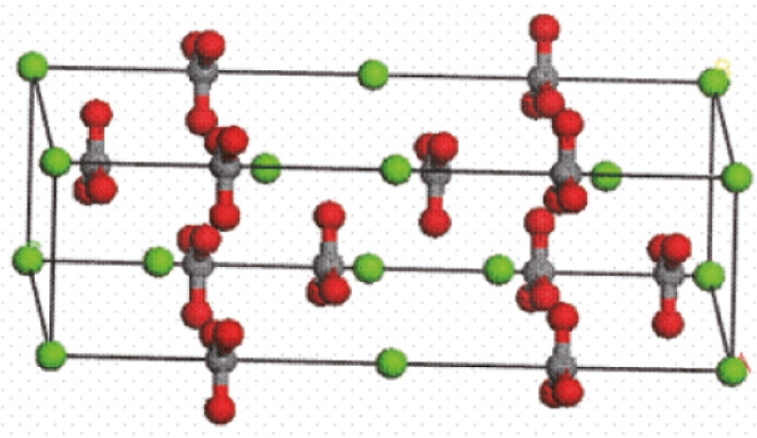

Fig. 1 Calcite atomic structure model Atomic designations: $\mathrm{C}$ (gray), $\mathrm{O}$ (red), $\mathrm{Ca}$ (green)

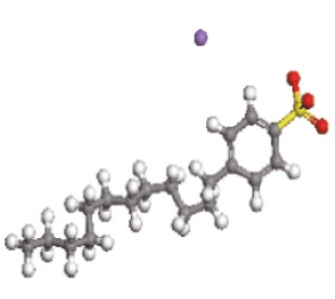

(a)

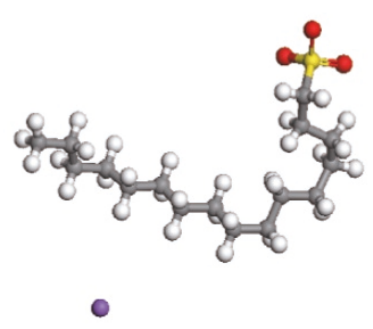

(b)

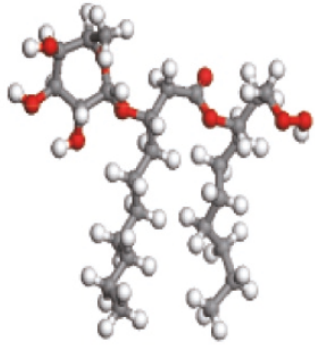

(c)

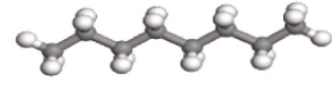

(d)

Fig. 2 Optimized model of surfactants and oil molecule (a) Sodium dodecyl benzene sulfonate; (b) Sodium hexadecyl sulfonate; (c) Rhamnolipid (biosurfactant); (d) Octane

\subsection{Simulation Method}

The super molecular adsorption model was constructed by adding oil-water-surfactant mixture onto the (1 $\overline{1} 0)$ surface of calcite. During the simulation process, crystal surface (1 10$)$ was regarded as an ideal plane and being fully frozen up, but the oil-water-surfactant mixture was regarded as freestate. The simulations were performed in the constant-volume and -temperature (NVT) ensemble (Heermann, 1996). The initial speed of molecules followed the Maxwell-Boltzmann distribution. A spherical cutoff of $0.95 \mathrm{~nm}$ was used both for short-range interactions and non-bonding Van der Waals and Coulomb interactions. The molecular interaction energy beyond the cut distance was corrected approximately by average density. Temperature was set to $373 \mathrm{~K}$ with a 100 ps simulation time. The initial and equilibrium structures of the super molecular system of rock-oil-water are shown in Fig. 3(a) and Fig. 3 (b), respectively. In this Figure, the first layer indicates the calcite, the gray color in the second layer indicates octane molecules and red color indicates water molecules. 


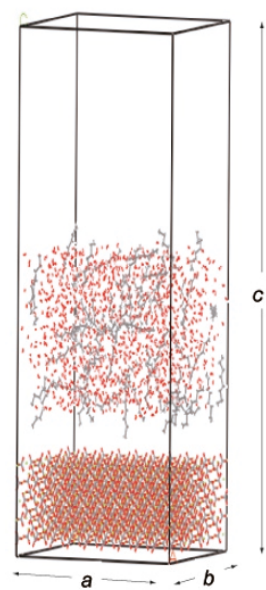

(a) The initial structure

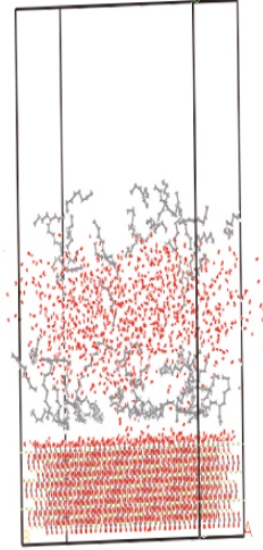

(b) The equilibrium structure
Fig. 3 Rock-oil-water super molecular structure model (super molecular structure parameter $a=4.4910 \mathrm{~nm}, b=5.1845 \mathrm{~nm}, c=8.1883 \mathrm{~nm}$ )

\section{Results and Discussion}

\subsection{Equilibrium}

The system equilibrium was judged by the fluctuation of temperature and energy. As an example, for a super molecular system with biosurfactant, the temperature profile and energy profiles at the last $20 \mathrm{ps}$ are shown in Fig. 4. It can be seen from Fig. 4 that temperature varies within a range of $10 \%$ around $373 \mathrm{~K}$ and energy varies within $0.1 \%$, which indicates that the super molecular system of oil-water and surfactant reached the steady state after $100 \mathrm{ps}$ MD simulation.

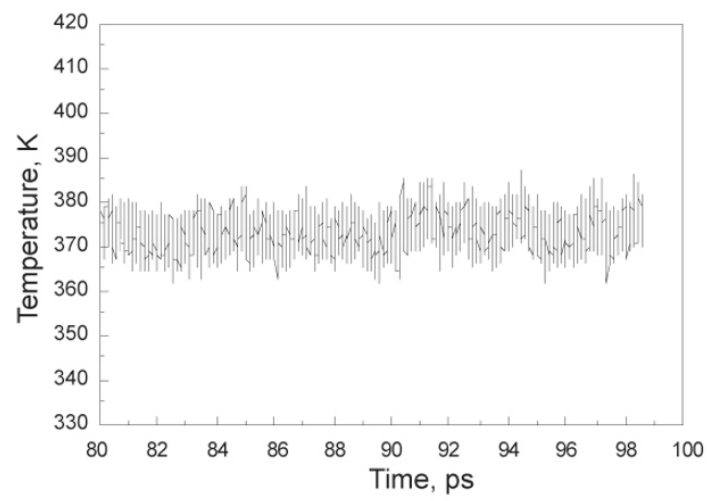

(a)

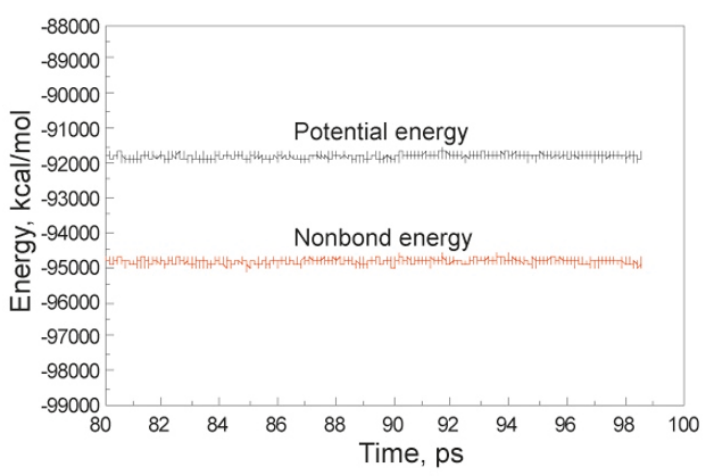

(b)

Fig. 4 Temperature (a) and energy (b) profiles of the simulated system

\subsection{Adsorption Energy}

While calculating the single point adsorption energy of the octane-calcite system, water and surfactant are removed from the system. While calculating the single point adsorption energy of water-calcite system, octane and surfactant are removed from the system. The system for MD simulation must be in equilibrium, and the surface, previously set up, is minimized. So during the simulation process, fix the entire surface, and in calculation of the single-point energy, free the surface.

On calcite, the adsorption energy of oil and water molecules is calculated as follows:

$$
\begin{aligned}
& E_{\text {oil-adsorption }}=E_{\text {surface-oil }}-\left(E_{\text {surface }}+E_{\text {oil }}\right) \\
& E_{\text {water-adsorption }}=E_{\text {surface-water }}-\left(E_{\text {surface }}+E_{\text {water }}\right)
\end{aligned}
$$

where $E_{\text {surface-oil }}, E_{\text {surface-water. }} E_{\text {surface }}, E_{\text {oil }}$, and $E_{\text {water }}$ represent the single point energy of the calcite-oil system, calcitewater system, calcite, oil molecule and water molecule, respectively. The binding energy is defined as the negative of the adsorption energy, that is $E_{\text {binding }}=-E_{\text {adsorption }}$. The bigger the binding energy, the more stable the adsorption structure.

As an example for the system of the biosurfactant, we calculated the adsorption energy separately at the time of 80 , $85,90,95$ and 100 ps, such as the results of Table 1 .

Table 1 Interaction energy of the biosurfactant system at different times

\begin{tabular}{cccccc}
\hline Time, $\mathrm{ps}$ & 80 & 85 & 90 & 95 & 100 \\
\hline$E_{\text {oil-interaction }}, \mathrm{kcal} / \mathrm{mol}$ & -18 & -21 & -22 & -19 & -22 \\
\hline
\end{tabular}

From Table 1 we can see, after $80 \mathrm{ps,} \mathrm{the} E_{\text {oil-interaction }}$ changes little. It is completely within the error range $( \pm 2)$, which shows that the system has reached equilibrium. Therefore, a configuration analysis in the state of equilibrium can represent the balanced ensemble average accurately.

Tables 2 and 3 give the calculated results for oil-calcite and water-calcite interaction systems respectively.

From Tables 2 and 3, it can be seen that the binding energy between oil and calcite decreases significantly when surfactant is added to the system. It means that the surfactant is effective to displace oil. But different surfactants have different effects according to the binding energy between water and calcite. In detail, both sodium dodecyl benzene sulfonate (with higher concentration) and rhamnolipid can enhance the hydrophilic and reduce the lipophilic properties, for it could increase the binding energy between water and calcite and decrease the binding energy between oil and calcite. Although sodium hexadecyl sulfonate could reduce the binding energy between water and rock, but the calcite is hydrophilic mainly when comparing to the interaction between oil and calcite (in Fig. 5). For the same surfactant, i.e. sodium dodecyl benzene sulfonate, a higher concentration is more effective. 
Table 2 Binding energy of octane on calcite $(1 \overline{1} 0)$ surface

\begin{tabular}{|c|c|c|c|c|c|}
\hline Surfactant & $\begin{array}{c}E_{\text {total }} \\
\mathrm{kcal} / \mathrm{mol}\end{array}$ & $\begin{array}{c}E_{\text {surface }} \\
\mathrm{kcal} / \mathrm{mol}\end{array}$ & $\begin{array}{c}E_{\text {oil }} \\
\mathrm{kcal} / \mathrm{mol}\end{array}$ & $\begin{array}{c}E_{\text {interaction }} \\
\mathrm{kcal} / \mathrm{mol}\end{array}$ & $\begin{array}{c}E_{\text {binding }} \\
\mathrm{kcal} / \mathrm{mol}\end{array}$ \\
\hline Without surfactant & -336024 & -336400 & 413 & -37 & 37 \\
\hline $\begin{array}{l}\text { Sodium dodecyl benzene sulfonate } \\
\qquad(\text { molecular number }=5)\end{array}$ & -336016 & -336400 & 409 & -25 & 25 \\
\hline Sodium hexadecyl sulfonate & -336039 & -336400 & 382 & -21 & 21 \\
\hline Rhamnolipid & -336014 & -336400 & 409 & -23 & 23 \\
\hline $\begin{array}{l}\text { Sodium dodecyl benzene sulfonate } \\
\qquad(\text { molecular number }=3)\end{array}$ & -335957 & -336400 & 475 & -32 & 32 \\
\hline
\end{tabular}

Table 3 Binding energy of water molecule on Calcite $(1 \overline{1} 0)$ surface

\begin{tabular}{|c|c|c|c|c|c|}
\hline Surfactant & $\begin{array}{c}E_{\text {total }} \\
\mathrm{kcal} / \mathrm{mol}\end{array}$ & $\begin{array}{c}E_{\text {surface }} \\
\mathrm{kcal} / \mathrm{mol}\end{array}$ & $\begin{array}{c}E_{\text {water }} \\
\mathrm{kcal} / \mathrm{mol}\end{array}$ & $\begin{array}{l}E_{\text {interaction }} \\
\mathrm{kcal} / \mathrm{mol}\end{array}$ & $\begin{array}{c}E_{\text {binding }} \\
\mathrm{kcal} / \mathrm{mol}\end{array}$ \\
\hline Without surfactant & -351675 & -336400 & -4386 & -10889 & 10889 \\
\hline $\begin{array}{l}\text { Sodium dodecyl benzene } \\
\text { sulfonate (molecular number }=5 \text { ) }\end{array}$ & -350865 & -336400 & -3349 & -11116 & 11116 \\
\hline Sodium hexadecyl sulfonate & -348972 & -336400 & -4077 & -8495 & 8495 \\
\hline Rhamnolipid & -351746 & -336400 & -3456 & -11890 & 11890 \\
\hline $\begin{array}{c}\text { Sodium dodecyl benzene } \\
\text { sulfonate (molecular number }=3 \text { ) }\end{array}$ & -349217 & -336400 & -4699 & -8118 & 8118 \\
\hline
\end{tabular}

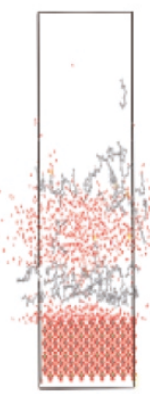

(a)

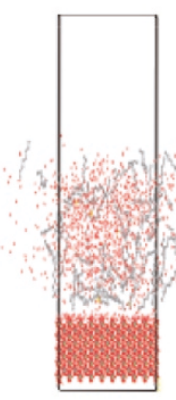

(b)

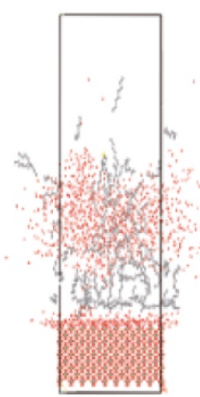

(c)
Fig. 5 Final structure model of rock surface a: with surfactant sodium dodecyl benzene sulfonate; $b$ : with surfactant sodium hexadecyl sulfonate; c: with surfactant rhamnolipid

It can be seen from Fig. 6 that the oil molecules are distributed on the calcite densely in absence of without surfactant. After adding surfactant sodium dodecyl benzene sulfonate, the oil molecules depart from the calcite, indicating that the surfactant is favorable to expelling oil.

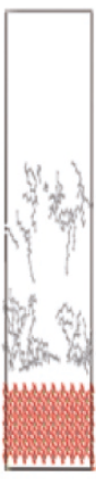

(a)

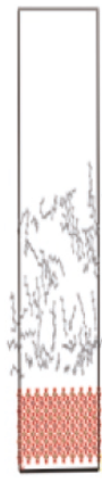

(b)

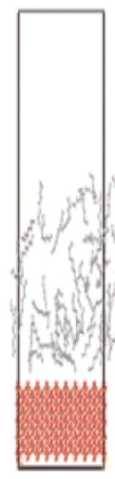

(c)

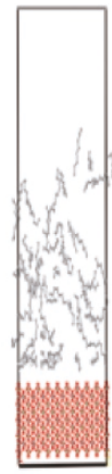

(d)

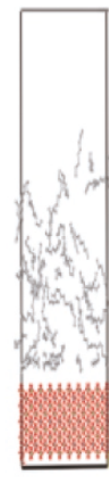

(e)
Fig. 6 Adsorption structure model of oil molecules on rock surface a: without surfactant; b: with surfactant sodium dodecyl benzene sulfonate $(n=5)$; c: with surfactant sodium hexadecyl sulfonate; d: with surfactant rhamnolipid; e: with surfactant sodium dodecyl benzene sulfonate $(n=3)$

\subsection{Radial distribution functions (RDF) of oil molecules}

To know more about the contribution of oil molecules on the calcite, and the influence of surfactant on the oil molecules distribution, we calculated the radical distribution 
function $g(r)$ of adsorption equilibrium system. Fig. 6 gives RDF $g(r)_{\text {total }}$ between octane molecules and calcite, and RDF $g(r)_{\mathrm{O}-\mathrm{H}}$ between $\mathrm{O}$ atoms and $\mathrm{H}$ atoms on the calcite.

In Fig. 7, the characteristic peaks of the radial distribution functions without surfactant appear at the same position as those of the RDF with surfactant sodium hexadecyl sulfonate. But the peak height without surfactant is higher than that with surfactant sodium hexadecyl sulfonate. After adding sodium hexadecyl sulfonate, both peaks fall noticably. This means that surfactant may increase the average distance between oil molecules and the surface of the calcite. With increasing distance from the surface the RDF with surfactant sodium hexadecyl sulfonate increases, which further indicated the oil
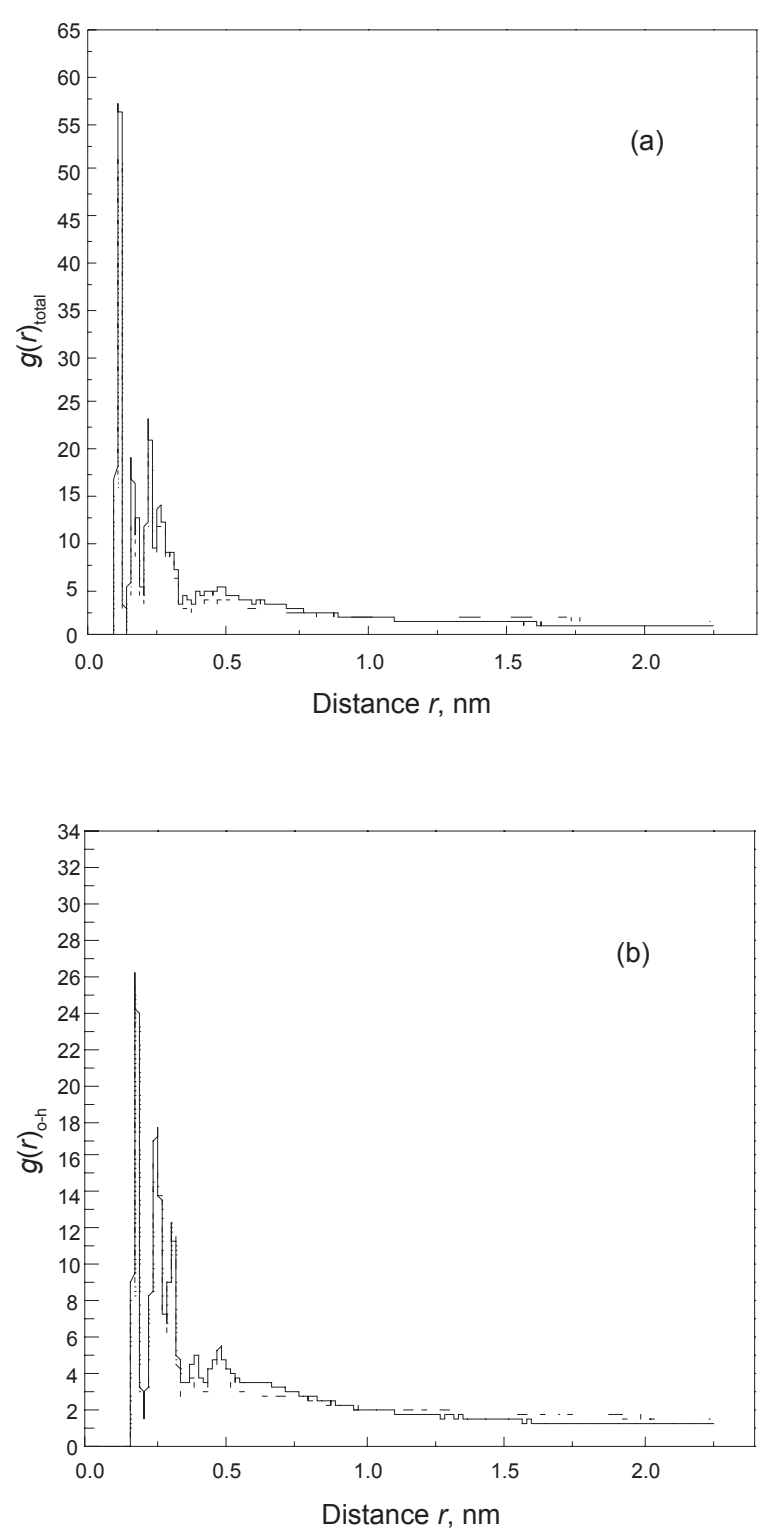

Fig. 7 Radial distribution functions $g(r)$ between oil molecules and crystal surface

(Solid line: without surfactant; dashed line: with surfactant sodium hexadecyl sulfonate)

a: the RDF $g(r)_{\text {total }}$ between octane molecules and rock surface;

$\mathrm{b}$ : the $\mathrm{RDF} g(r)_{\mathrm{O}-\mathrm{H}}$ between $\mathrm{O}$ atoms and $\mathrm{H}$ atoms on the rock surface molecules offset in the surfactant situation. This is consistent with the calculation results from binding energy.

\section{Conclusions}

In this paper, by selecting octane as the representative component of oil and considering rock surface as a perfect calcite crystal surface, the structure of interface adsorption system and the wetting action are investigated at micro molecular level. It was found that three kinds of surfactants i.e. sodium hexadecyl sulfonate, sodium dodecyl benzene sulfonate and rhamnolipid biosurfactant, could weaken the binding energy between water and calcite. The watercalcite and oil-calcite interaction energy analyses revealed that rhamnolipid, and sodium dodecyl benzene sulfonate at a higher concentration, might enhance the surface hydrophilic property and reduce the surface lipophilic property. For actual rock surfaces and the complicated oil components further work is required.

\section{Acknowledgements}

This work was supported by the Venture Innovation Fund of PetroChina Company Limited (07-06D-01-04-02-10) and CNPC Innovative Fund for Middle-aged and Youth of China (CNPC2006-2008).

\section{Reference}

Bi Z C, Qian Y Y, Xu F and Yu J Y. Investigation on oil film formation on silica surfaces in relation to their wettability. Oilfield Chemistry. 1997.14:345-348(in Chinese)

Boek E S, Coveney P V and Skipper N T. Molecular modeling of clay hydration: A study of hysteresis loops in the swelling curves of sodium montmorillonites. Langmuir. 1995. 11:4629

Boek E S, Coveney P V and Skipper N T. Monte Carlo molecular modeling studies of hydrated Li-, $\mathrm{Na}-$, and $\mathrm{K}$-smectites: understanding the role of potassium as a clay swelling inhibitor. J. Am. Chem.Soc. 1995. 117: 12608

Capkova P, Burda J V, Weiss Z and Schenk H. Modelling of anilinevermiculite and tetramethylammonium-vermiculite. J. Mol. Model.1999. 5: 8

de Leeuw N H and Parker S C. Atomistic simulation of the effect of molecular absorption of water on the surface structure and energies of calcite surfaces. J. Chem. Soc., Faraday Trans. 1997. 93: 467-475

Delville A. Modeling the clay-water interface. Langmuir. 1991. 7: 547

Graf D L. Crystallographic tables for the rhombohedral carbonates. American Mineralogist. 1961. 46: 1283-1316

Hädicke E, Rieger J, Rau I U and Boeckh D. Molecular dynamics simulations of the incrustation inhibition by polymeric additives. Phys.Chem.Chem.Phys. 1999. 1: 3891-3898

He C Z and Hua M Q. Reservoir Physical Chemistry. Xi'an: Electronic Science and Technology University Press.1995 (in Chinese)

Heermann D W. Computer Simulation Methods in Theoretical Physics. Qin Ke-cheng. Beijing: Beijing University Press. 1996

Kendall T A and Martin S T. Water-induced reconstruction that affects mobile ions on the surface of calcite. J. Phys. Chem. A. 2007. 111: 505-514

Kerisit S, Parker S C and Harding J H. Atomistic simulation of the dissociative adsorption of water on calcite surfaces. J. Phys. Chem. B. 2003. 107: 7676-7682

Kerisit S and Parker S C. Free energy of adsorption of water and 
metal ions on the $\{1 \overline{01} 4\}$ calcite surface. J. Am. Chem. Soc. 2004. 126:10152-10161

Liang Y, Lea A S, Baer D R and Engelhard M H. Structure of the cleaved $\mathrm{CaCO}_{3}$ (104) surface in an aqueous environment. Surf. Sci. 1996. 351:172-182

Nicholas J B, Winans R E, Harrison R J, et al. Ab initio molecular orbital study of the effects of basis set size on the calculated structure and acidity of hydroxyl groups in framework molecular sieves. J. Phys. Chem. 1992. 96: 10247

Nicholas J B, Winans R E, Harrison R J, et al. An ab initio investigation of disiloxane using extended basis sets and electron correlation. J. Phys. Chem. 1992. 96: 7958

Rieger J, Hädicke E, Rau I U and Boeckh D. A rational approach to the mechanisms of incrustation inhibition by polymeric additives. Tenside Surfactants Deterg ents. 1997. 34(6): 430

Shevchenko S M, Bailey G W and Akim L G. The conformational dynamics of humic polyanions in model organic and organo-mineral aggregates. THEOCHEM. 1999. 460: 179

Shi W Y, Wang F Y, Xia M Z, et al. Molecular dynamics simulation of interaction between carboxylate copolymer and calcite crystal. 2006. 64(17):1817-1823

Stipp S L and Hochella M F. Structure and bonding environments at the calcite surface as observed with X-ray photoelectron spectroscopy (XPS) and low-energy electron diffraction (LEED). Geochim. Cosmochim. Acta. 1991. 55: 1723-1736

Sun H. COMPASS: An ab initio force field optimized for condensedphase applications _ Overview with details on alkane and benzene compounds. J. Phys. Chem. B. 1998. 102: 7338

Teppen B J, Rasmussen K, Bertsch P M, et al. Molecular dynamics modeling of clay minerals. 1. gibbsite, kaolinite, pyrophyllite, and beidellite. J. Phys. Chem. B. 1997. 10:1579

(Edited by Zhu Xiuqin) 